\title{
Costs of elective vs emergency cholecystectomy in diabetic patients
}

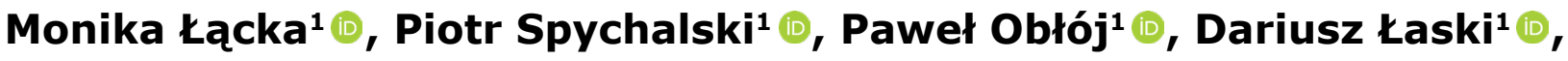

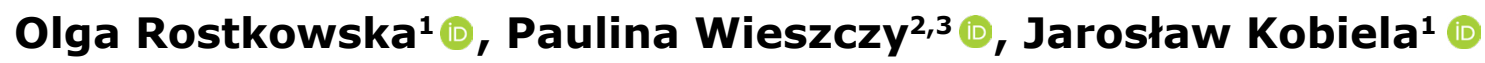

${ }^{1}$ Department of General, Endocrine and Transplant Surgery of University Clinical Center in Gdańsk, Poland

${ }^{2}$ Central Coordination Center for Cervical Cancer Screening Program, Department of Cancer Prevention,

Maria Sklodowska-Curie Institute-Oncology Center, Warsaw, Poland

${ }^{3}$ Department of Gastroenterology, Hepatology and Oncology, Medical Center for Postgraduate Education, Warsaw, Poland

\begin{abstract}
Introduction: Hospitalization costs of diabetic patients are estimated to be higher than non-diabetic. Literature on the topic is however limited. The aim of this study was to compare the costs of elective and emergency cholecystectomy of diabetic and non-diabetic patients. Material and methods: A retrospective analysis involved diabetic versus non-diabetic age- and sex-matched patients who underwent emergency and elective cholecystectomy at a single center in Poland between 2016-2019. Results: The total costs of an elective cholecystectomy were $739.31 \pm 423.07$ USD for diabetic patients and 797.14 \pm 772.24 USD for non-diabetic patients $(p=0.51)$. Whereas emergency cholecystectomy total costs were $3950.72 \pm 2856.83$ USD (diabetic patients) and $2464.31 \pm$ 1718.21 USD (non-diabetic patients) $(p=0.04)$. The difference in total costs between elective cholecystectomy vs emergency cholecystectomy in both groups (diabetic vs non-diabetic patients) was statistically significant ( $p<0.01$ vs $p<0.05$ respectively). Conclusions: In this study we demonstrated that emergency cholecystectomy is associated with a significant increase in hospitalization costs, particularly in diabetic patients. This suggests that early qualification of diabetic patients for an elective cholecystectomy could be beneficial for both diabetic patients and public health insurers.
\end{abstract}

Keywords: diabetes $\cdot$ elective cholecystectomy $\cdot$ emergency cholecystectomy $\cdot$ costs of hospitalization

\section{Citation}

Łącka M, Spychalski P, Obłój P, Łaski D, Rostkowska O, Wieszczy P, Kobiela J. Costs of elective vs emergency cholecystectomy in diabetic patients. Eur J Transl Clin Med. 2020;3(2):37-43.

DOI: $10.31373 /$ ejtcm/128963

\section{Corresponding author:}

Monika Łącka, Department of General, Endocrine and Transplant Surgery of University Clinical Center in Gdańsk, Poland

e-mail: mlacka@gumed.edu.pl

No external funds.

Available online: www.ejtcm.gumed.edu.pl

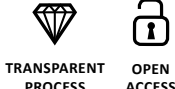

Copyright ${ }^{\circledR}$ Medical University of Gdańsk

This is Open Access article distributed under the terms of the Creative Commons Attribution-ShareAlike 4.0 International. 


\section{Introduction}

According to the latest World Health Organization data, the estimated number of people suffering from diabetes worldwide is $\mathbf{4 2 2}$ million and the incidence of diabetes is increasing rapidly [1]. Because of its many complications, diabetes mellitus is associated with significant costs in public healthcare systems around the globe $[2,3]$. Acute cholecystitis in diabetic patients is often complicated by gangrenous cholecystitis [1], peritonitis, preoperative perforation, impaired wound healing, infections, increased risk of cardiovascular events and renal failure [4-11]. For this reason, diabetic patients hospitalisation costs are estimated to be higher than non-diabetic. Literature on the topic is limited and mostly concludes that immediate intervention leads to a decrease in costs and shortens the length of hospital stay [12-16]. The aim of this study was to compare the costs of elective and emergency cholecystectomy of diabetic and non-diabetic patients.

\section{Materials and methods}

A retrospective analysis involved patients who underwent emergency and elective cholecystectomy at the Department of General, Endocrine and Transplant
Surgery of University Clinical Center in Gdańsk (Poland) between 2016 and 2019. Patients were assigned to diabetic group whenever diabetes mellitus of any type was identified in admission work-up. Using institutional registries we identified a total of 661 patients who underwent emergency cholecystectomy, of whom 70 patients had diabetes and 591 were non-diabetic. A random sample of 16 diabetic patients was included to the study depending on admission data criteria and was used to assign an age- and sex-adjusted control group.

A total of 1608 patients who underwent elective cholecystectomy where identified in institutional registries, of whom 135 had diabetes and 1473 were non-diabetic patients. A random sample of 20 diabetic patients were included to the study depending on admission data criteria. The control group of 80 patients was age- and sex-matched in a 4:1 ratio (Non-diabetic: Diabetic) (see Figure 1, Table 1).

The following were the criteria of inclusion into the study: unplanned or planned admission depending on group, cholecystectomy performed within 72 $\mathrm{h}$ of admission, and the availability of complete report of hospitalization costs in the electronic system. Patients were assigned to the diabetic group whenever diabetes mellitus of any type was identified in the admission work-up. The exclusion criteria included the lack of data on the costs of hospitalization, incomplete

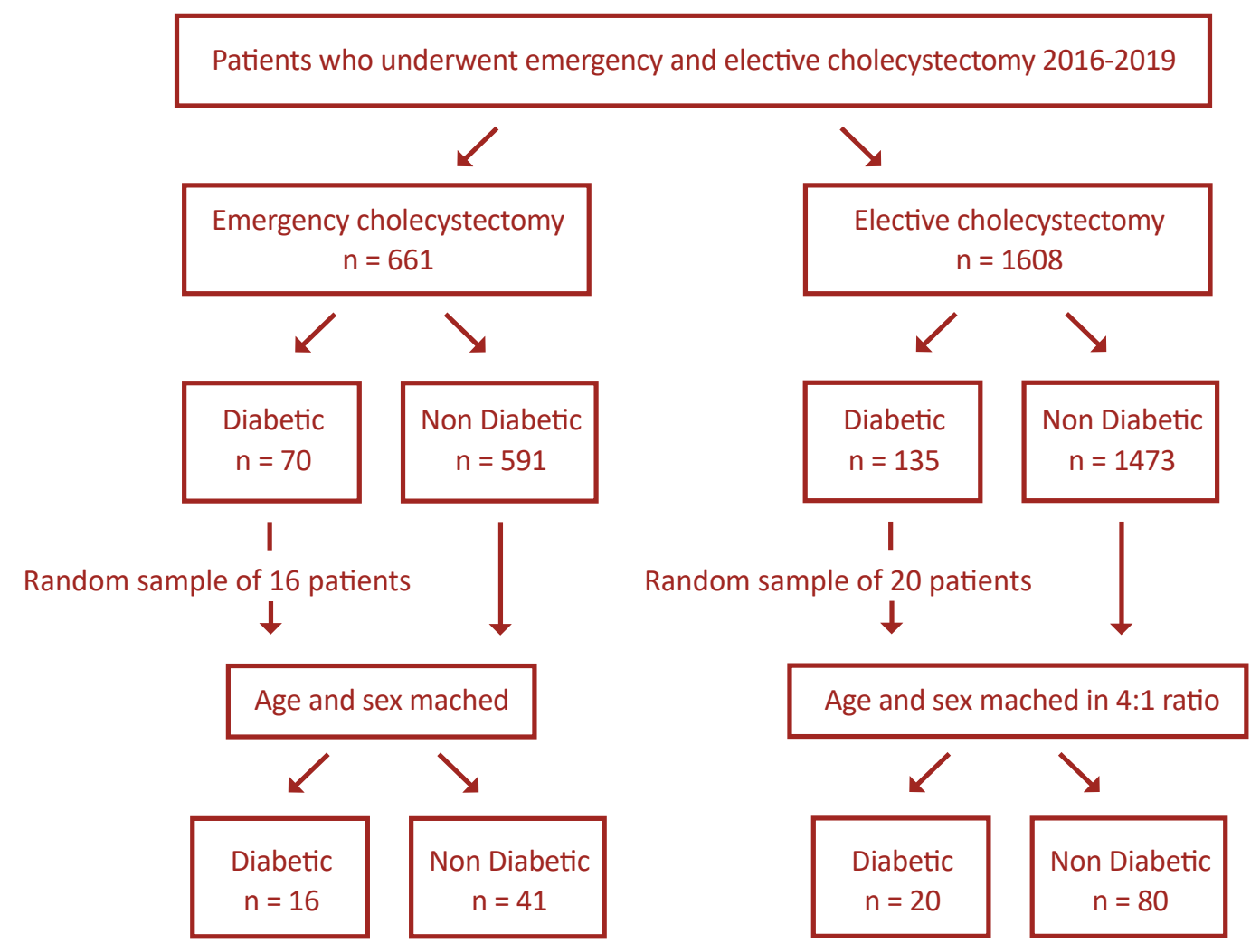

Figure 1. Flowchart illustrating patient selection 
Table 1. Age distribution of patients in the emergency vs elective cholecystectomy group

\begin{tabular}{|c|c|c|c|c|}
\hline Age & Diabetic & Non-diabetic & Diabetic & Non-diabetic \\
\hline $\mathbf{8 0}$ & 1 & 5 & 1 & 6 \\
\hline $\mathbf{4 1 - 6 0}$ & 7 & 16 & 11 & 44 \\
\hline $\mathbf{6 1 - 8 0}$ & 7 & 15 & 8 & 30 \\
\hline $\mathbf{8} 80$ & 1 & 5 & 0 & 0 \\
\hline
\end{tabular}

to viable data from the point of admission was limited, and therefore group size was limited as well. The downgrading of data quality was ruled out by the mean group size.

\section{Total hospitalization cost}

In a group of patients who underwent elective cholecystectomy, the total costs for diabetic patients were $739.31 \pm 423.07$ USD [median: 536.15 USD; range: 287.20 USD 1606.67 USD] and for non-diabetic was $797.14 \pm 772.24$ USD ( $p=0.51)$

data on time or course of hospitalization, more than one surgery performed that was not related to cholecystectomy and its complications during the same hospitalization, cholecystectomy performed during hospitalization for a different reason.

Calculation of the direct costs of the Emergency Department included: medical imaging, medicines, consultations, laboratory tests, procedures performed and equipment. Whereas the General Surgery Department costs taken into account (in emergency and elective cholecystectomy) were: medical imaging, medicines, consultations, histopathology, laboratory works, procedures performed, equipment, operating room cost, cost of stay. Total costs of emergency cholecystectomy were a sum of costs incurred at the Emergency and General Surgery Departments. Total hospitalization costs taken into account for elective cholecystectomy were all generated at the General Surgery Department. Costs were converted from Polish Złoty (PLN) to US Dollars (USD) using the National Bank of Poland exchange rates from 11 September 2019. Descriptive analysis included medians, means and standard deviations. In comparative analysis U Mann-Whitney test, Student's t-test and the $\mathrm{X}^{2}$ test were used. Distribution was tested using Shapiro-Wilk test. Statistical significance was accepted at $p<0.05$. Statistical analyses were performed using Statistica 13.3 (TIBCO Software, Palo Alto, United States).

\section{Results}

A group of 57 patients (16 with diabetes and 41 non-diabetic) who underwent emergency cholecystectomy was analyzed. A total of 100 patients who underwent elective cholecystectomy were included to the study, 20 patients with diabetes and 80 patients without. Patients were matched in the group by age and sex. In the emergency group the access [median: 651.47 USD; range: 281.75 - 6089.41 USD]. In a group of patients who underwent emergency cholecystectomy total costs for diabetic patients were $3950.72 \pm 2856.83$ USD [median: 3188.67 USD; range: $753.23-10760.15$ USD] and $2464.31 \pm 1718.21$ USD ( $p=0.04$ ) [median: 2087.56 USD; range: 689.26 USD - 10950.16 USD] for non-diabetic patients. The difference in total costs between elective cholecystectomy and emergency cholecystectomy in both groups (diabetic and non-diabetic patients) was statistically significant ( $p<0.01, p<0.05$ respectively) (see Table 2 and Table 3).

Table 2. Mean emergency ward costs in emergency cholecystectomy group

\begin{tabular}{|c|c|c|c|}
\hline & Diabetic & Non-diabetic & p-value \\
\hline Medical imaging & 79.52 USD & 50.29 USD & 0.495 \\
\hline Consultations & 31.13 USD & 23.55 USD & 0.356 \\
\hline Procedures & 32.64 USD & 35.33 USD & 0.670 \\
\hline Laboratory tests & 23.24 USD & 20.91 USD & 0.477 \\
\hline Medicines & 3.47 USD & 4.88USD & 0.279 \\
\hline Equipment & 8.35 USD & 6.12 USD & 0.657 \\
\hline Other & 0 USD & 0 USD & 0.000 \\
\hline Total* & $\begin{array}{c}178.48 \\
\text { USD }\end{array}$ & 141.20 USD & 0.505 \\
\hline
\end{tabular}

*Due to the applied approximations, individual costs cannot be summed up to a total cost. 
Table 3. Mean general surgery ward costs in emergency vs planned cholecystectomy group

\begin{tabular}{|c|c|c|c|c|c|c|}
\hline \multicolumn{1}{|c|}{ Diabetic } & Non-diabetic & p-value & Diabetic & Non-diabetic & p-value \\
\hline Cost of stay & 1416.86 USD & 758.01 USD & 0.015 & 329.19 USD & 424.29 USD & 0.829 \\
\hline Operation room & 628.81 USD & 577.49 USD & 0.676 & 605.53 USD & 566.15 USD & 0.113 \\
\hline Histopathology & 31.56 USD & 11.24 USD & 0.901 & 9.40 USD & 11.05 USD & 0.595 \\
\hline Laboratory tests & 73.86 USD & 29.13 USD & 0.012 & 11.96 USD & 15.14 USD & 0.510 \\
\hline Medicines & 371.23 USD & 178.93 USD & 0.083 & 17.42 USD & 34.10 USD & 0.561 \\
\hline Medical imaging & 87.28 USD & 34.47 USD & 0.066 & 0 USD & 0 USD & 0.000 \\
\hline Equipment & 252.53 USD & 98.09 USD & 0.001 & 61.44 USD & 63.59 USD & 0.638 \\
\hline Consultations & 26.36 USD & 12.02 USD & 0.050 & 0 USD & 0 USD & 0.000 \\
\hline $\begin{array}{c}\text { Total } \\
\text { hospitalization* }\end{array}$ & 3950.72 USD & 2464.31 USD & 0.040 & 739.31 USD & 797.14 USD & 0.515 \\
\hline
\end{tabular}

*Due to the applied approximations, individual costs cannot be summed up to a total cost.

\section{Procedure-related costs}

Procedure-related costs included General Surgery Department procedures plus costs of operating theatre (Table 3). Procedure costs in the emergency group were $724.60 \pm 416.92$ USD for diabetic patients and $625.26 \pm 304.78$ USD for non-diabetic patients $(p=$ $0.613)$. Elective cholecystectomy group costs were $605.53 \pm 246.04$ USD for diabetic patients and 566.15 \pm 325.37 USD for non-diabetic patients, $p=0.113$. Differences in procedural costs between patients in diabetic and non-diabetic groups undergoing emergency cholecystectomy and those who underwent planned cholecystectomy were not statistically-significant, $p=$ 0.824 and $p=0,992$ respectively.

\section{Other costs}

Medical imaging costs were only applicable to the emergency cholecystectomy group and at the General Surgery Department they were 87.28 \pm 152.21 USD for diabetic patients and $34.47 \pm 70.87$ USD for non-diabetic patients, $p=0,066$. Whereas at the Emergency Department they were $79.52 \pm 103.90$ USD for diabetic patients and $50.29 \pm 75.10$ USD for non-diabetic, $p=0495$. Other types of costs were not statistically significant with all $\mathrm{p}$-values greater than 0.05 (see Table 2 and Table 3).

\section{Length of stay}

Mean length of stay counted in days for patients undergoing elective surgery was: $3.12 \pm 2.96$ for diabetic patients and $2.35 \pm 0.87$ for non-diabetic patients, ( $p=0.555$ ). Difference between elective and emergency cholecystectomy was statistically significant both for diabetic $p<0.001$ and for non-diabetic patients $p<$ 0.001 . For emergency cholecystectomy mean length of stay was $10.62 \pm 8.15$ for diabetics and $5.49 \pm 3.96$ for non-diabetic patients $p=0.017$ ).

\section{Discussion}

To our knowledge, this is the first report of specific hospitalization costs of diabetic and non-diabetic patients undergoing elective and emergency cholecystectomy. Our results suggest that emergent intervention in diabetic and non-diabetic group of patients leads to greater total costs of hospitalization, 
costs of stay and procedure-related costs compared to planned cholecystectomy $(p<0.05)$. Furthermore, a significant difference between emergency hospitalization costs of diabetic and non-diabetic patients was found ( $p=0.04$ ), while there was no significant difference in cost between diabetic and non-diabetic patients in elective hospitalisation (see Table 3). This suggests that acute cholecystitis is not only burdened with higher risk of complications but also with a much higher cost. This may be another important factor underlining the need for diabetes patients to undergo elective surgery. However according to EASL guidelines, routine surgical treatment is not recommended for patients with asymptomatic gallbladder stones [17]. In our analysis the costs of hospitalisation were greater in emergency intervention both in diabetic and non-diabetic patients. It was reported numerous times, that elective surgery carries lower risk of complications $[12,15,18,19]$. Perhaps this is due to the fact that patients undergoing elective surgery not only do not have a fast progressing emergency condition but also are better prepared for surgery i.e. intentional weight loss, adequate glycemic control, appropriate treatment of possible arrhythmias and hypertension. [20]

Treatment of complications significantly prolong the hospital stay directly leading to increased costs of hospitalization. Costs of emergency surgery in diabetic patients are significantly higher $(p=0.015)$ than in non-diabetic. This is due to increased levels of complications intraoperatively and in postoperative period in diabetic patients with acute cholecystitis in comparison to-non diabetics [11,19,21-24].

Increase of procedure-related costs could be explained by frequently more advanced disease at admission of diabetic patients with acute cholecystitis. As reported previously, diabetics more often present with gangrenous cholecystitis, gall bladder perforation or emphysematous cholecystitis [1,7,25-28]. This leads to extended duration of surgery and increased use of materials during surgical interventions resulting in increased costs of surgery [29]. Increased rate of complications such as wound infections or impaired wound healing requires additional instrumental interventions during post-operative stay and thus generates further costs [30,31].

Imaging costs were a significant part of increased costs in emergency patients because in our study patients undergoing elective cholecystectomy obtained imaging prior to their admission Furthermore, medical imaging during hospital stay was required due to emerging complications. It can be considered one of the major cost-generating factors along with procedures and the length of stay.

In our study, the length of hospitalization is a measure of effectiveness. There is a statistically significant difference between the length of hospitalization of elective and emergency patients in both groups diabetic and non-diabetic $(p<0.001)$ and the emergency patients' length of stay was longer.

There is no significant difference between the length of stay of diabetic and non-diabetic patients undergoing elective surgery. This is in contrast to emergency procedures. The length of stay of patients with diabetes operated urgently was statistically significantly longer than in non-diabetic patients $(10.62 \pm 8.15$ vs $5.49 \pm 3.96, p=0.017)$. This may be due to a more locally advanced disease and more common complications. Regardless of the reason above, our study clearly shows that diabetic patients may benefit from elective cholecystectomy.

\section{Study limitations}

First of all, this study is limited due to its retrospective nature. We performed a univariate analysis and did not involve potential cofactors such as glycaemia control, comorbidities and medications. Furthermore, the calculated costs might differ in other health care systems and crude values might vary substantially. However, we believe that the differences shown seem universal due to common cost-generating factors.

\section{Conclusion}

In this study we demonstrated that an emergency cholecystectomy in a diabetic patient is associated with greater costs when compared to a planned cholecystectomy. While there are no differences in the costs of elective hospitalizations, there is a statistically significant difference in the costs of emergency surgery between diabetic and non-diabetic patients. As cholelithiasis in diabetic patients can often be diagnosed at its asymptomatic stage, we suggest that qualifying these patients to an elective cholecystectomy early on may lead to fewer serious complications and a decrease in total costs of hospitalization. Although elective cholecystectomy is not supported in current guidelines, it seems that such approach could be beneficial for both diabetic patients and public health insurers. (European Association for the Study of the Liver (EASL), 2016) 


\section{References}

1. Gomes CA, Soares C, Di Saverio S, Sartelli M, de Souza Silva PG, Orlandi AS, et al. Gangrenous cholecystitis in male patients: A study of prevalence and predictive risk factors. Ann Hepato-Biliary-Pancreatic Surg [Internet]. 2019 Feb;23(1):34. Available from: https://synapse.koreamed.org/DOlx.php?id=10.14701/ahbps.2019.23.1.34

2. Lee CMY, Goode B, Nørtoft E, Shaw JE, Magliano DJ, Colagiuri S. The cost of diabetes and obesity in Australia. J Med Econ [Internet]. 2018 Oct 3;21(10):1001-5. Available from: https://www.tandfonline.com/doi/full/10.1080/13696998 .2018 .1497641

3. Marcellusi A, Viti R, Mecozzi A, Mennini FS. The direct and indirect cost of diabetes in Italy: a prevalence probabilistic approach. Eur J Heal Econ [Internet]. 2016 Mar 27;17(2):139-47. Available from: http://link.springer.com/10.1007/ s10198-014-0660-y

4. Karamanos E, Sivrikoz E, Beale E, Chan L, Inaba K, Demetriades D. Effect of diabetes on outcomes in patients undergoing emergent cholecystectomy for acute cholecystitis. World J Surg [Internet]. 2013 Oct 16;37(10):2257-64. Available from: https://doi.org/10.1007/s00268-013-2086-6

5. Chuang S-C, Lee K-T, Chang W-T, Wang S-N, Kuo K-K, Chen J-S, et al. Risk factors for wound infection after cholecystectomy. J Formos Med Assoc [Internet]. 2004 Aug;103(8):607-12. Available from: http://www.ncbi.nlm.nih.gov/pubmed/15340659

6. Michalia M, Kompoti M, Koutsikou A, Paridou A, Giannopoulou P, Trikka-Graphakos E, et al. Diabetes mellitus is an independent risk factor for ICU-acquired bloodstream infections. Intensive Care Med [Internet]. 2009 Mar 20;35(3):44854. Available from: http://link.springer.com/10.1007/s00134-008-1288-0

7. Bourikian S, Anand RJ, Aboutanos M, Wolfe LG, Ferrada P. Risk factors for acute gangrenous cholecystitis in emergency general surgery patients. Am J Surg [Internet]. 2015 Oct;210(4):730-3. Available from: https://doi.org/10.1016/i.amjsurg.2015.05.003

8. Hickman MS. Acute Cholecystitis in the Diabetic. Arch Surg [Internet]. 1988 Apr 1;123(4):409. Available from: http:// archsurg.jamanetwork.com/article.aspx?doi=10.1001/archsurg.1988.01400280015001

9. Andercou O, Olteanu G, Mihaileanu F, Stancu B, Dorin M. Risk factors for acute cholecystitis and for intraoperative complications. Ann Ital Chir [Internet]. 2017;88:318-25. Available from: http://www.ncbi.nlm.nih.gov/pubmed/29068324

10. Stanisic V, Milicevic M, Kocev N, Stojanovic M, Vlaovic D, Babic I, et al. Prediction of difficulties in laparoscopic cholecystectomy on the base of routinely available parameters in a smaller regional hospital. Eur Rev Med Pharmacol Sci [Internet]. 2014;18(8):1204-11. Available from: http://www.ncbi.nlm.nih.gov/pubmed/24817296

11. Łącka M, Spychalski P, Dobrzycka M, Rostkowska O, Kobiela J. Acute cholecystitis in patients with diabetes mellitus systematic review. Eur J TransI Clin Med [Internet]. 2020 Jan 9;2(2):71-9. Available from: https://ejtcm.gumed.edu. $\mathrm{pl} / \mathrm{articles} / 53$

12. Gelbard R, Karamanos E, Teixeira PG, Beale E, Talving P, Inaba K, et al. Effect of delaying same-admission cholecystectomy on outcomes in patients with diabetes. Br J Surg [Internet]. 2014 Jan;101(2):74-8. Available from: http://doi.wiley. com/10.1002/bjs.9382

13. Roulin D, Saadi A, Di Mare L, Demartines N, Halkic N. Early Versus Delayed Cholecystectomy for Acute Cholecystitis, Are the 72 hours Still the Rule? Ann Surg [Internet]. 2016 Nov;264(5):717-22. Available from: http://journals.Iww. com/00000658-201611000-00006

14. Özkardeş AB, Tokaç M, Dumlu EG, Bozkurt B, Çiftçi AB, Yetişir F, et al. Early Versus Delayed Laparoscopic Cholecystectomy for Acute Cholecystitis: A Prospective, Randomized Study. Int Surg [Internet]. 2014 Jan 1;99(1):56-61. Available from: https://meridian.allenpress.com/international-surgery/article/99/1/56/115847/Early-Versus-Delayed-Laparoscopic-Cholecystectomy

15. Thangavelu A, Rosenbaum S, Thangavelu D. Timing of Cholecystectomy in Acute Cholecystitis. J Emerg Med [Internet]. 2018 Jun;54(6):892-7. Available from: https://linkinghub.elsevier.com/retrieve/pii/S0736467918302324

16. Gutt CN, Encke J, Köninger J, Harnoss J-C, Weigand K, Kipfmüller K, et al. Acute Cholecystitis. Ann Surg [Internet]. 2013 Sep;258(3):385-93. Available from: http://journals.Iww.com/00000658-201309000-00002

17. European Association for the Study of the Liver (EASL). Electronic address: easloffice@easloffice.eu. EASL Clinical Practice Guidelines on the prevention, diagnosis and treatment of gallstones. J Hepatol [Internet]. 2016 Jul;65(1):146-81. Available from: https://linkinghub.elsevier.com/retrieve/pii/S0168827816300320

18. Ikard RW. Gallstones, cholecystitis and diabetes. Surg Gynecol Obstet [Internet]. 1990 Dec;171(6):528-32. Available from: http://www.ncbi.nlm.nih.gov/pubmed/2244290 
19. de Siqueira Corradi MB, D Ávila R, Duim E, Rodrigues CIS. Risk stratification for complications of laparoscopic cholecystectomy based on associations with sociodemographic and clinical variables in a public hospital. Am J Surg [Internet]. 2019 May 15; Available from: https://doi.org/10.1016/j.amjsurg.2019.05.005

20. Iqbal U, Green JB, Patel S, Tong Y, Zebrower M, Kaye AD, et al. Preoperative patient preparation in enhanced recovery pathways. J Anaesthesiol Clin Pharmacol [Internet]. 2019 Apr;35(Suppl 1):S14-23. Available from: http://www.ncbi.nlm. nih.gov/pubmed/31142954

21. Terho PM, Leppäniemi AK, Mentula PJ. Laparoscopic cholecystectomy for acute calculous cholecystitis: a retrospective study assessing risk factors for conversion and complications. World J Emerg Surg [Internet]. 2016 Dec 16;11(1):54. Available from: http://wjes. biomedcentral.com/articles/10.1186/s13017-016-0111-4

22. Paajanen $H$, Suuronen S, Nordstrom P, Miettinen P, Niskanen L. Laparoscopic versus open cholecystectomy in diabetic patients and postoperative outcome. Surg Endosc [Internet]. 2011 Mar 27;25(3):764-70. Available from: http://link. springer.com/10.1007/s00464-010-1248-y

23. Jaafar G, Hammarqvist F, Enochsson L, Sandblom G. Patient-Related Risk Factors for Postoperative Infection After Cholecystectomy. World J Surg [Internet]. 2017 Sep 20;41(9):2240-4. Available from: http://link.springer.com/10.1007/ $\underline{\text { s00268-017-4029-0 }}$

24. Al-Mulhim AS. Gastroparesis post-laparoscopic cholecystectomy in diabetic patients. Updates Surg [Internet]. $2017 \mathrm{Mar}$ 10;69(1):89-93. Available from: http://link.springer.com/10.1007/s13304-017-0417-0

25. Alves C, Casqueiro J, Casqueiro J. Infections in patients with diabetes mellitus: A review of pathogenesis. Indian J Endocrinol Metab [Internet]. 2012 Mar;16(7):27. Available from: http://www.ijem.in/text.asp?2012/16/7/27/94253

26. Önder A, Kapan M, Ülger BV, Oğuz A, Türkoğlu A, Uslukaya Ö. Gangrenous Cholecystitis: Mortality and Risk Factors. Int Surg [Internet]. $2015 \mathrm{Feb}$ 1;100(2):254-60. Available from: https://meridian.allenpress.com/international-surgery/article/100/2/254/175357/Gangrenous-Cholecystitis-Mortality-and-Risk

27. Shirah BH, Shirah HA, Saleem MA, Chughtai MA, Elraghi MA, Shams ME. Predictive factors for gangrene complication in acute calculous cholecystitis. Ann Hepato-Biliary-Pancreatic Surg [Internet]. 2019 Aug;23(3):228. Available from: https:// synapse.koreamed.org/DOlx.php?id=10.14701/ahbps.2019.23.3.228

28. Lallemand B, De Keuleneer R, Maassarani F. Emphysematous cholecystitis. Acta Chir Belg [Internet]. 2003 Apr;103(2):2302. Available from: http://www.ncbi.nlm.nih.gov/pubmed/12768870

29. S. A. Ziaee, S. A. Fanaie, R. Khatib NK. Outcome of cholecystectomy in diabetic patients. Indian J Surg [Internet]. 2005;67(2):87-9. Available from: https://www.researchgate.net/profile/Ali Ziaee4/publication/27796262 Outcome of cholecystectomy in diabetic patients/links/574eb3a708aec50945ba4c6d.pdf

30. Boehme J, McKinley S, Michael Brunt L, Hunter TD, Jones DB, Scott DJ, et al. Patient comorbidities increase postoperative resource utilization after laparoscopic and open cholecystectomy. Surg Endosc [Internet]. 2016 Jun 1;30(6):2217-30. Available from: http://link.springer.com/10.1007/s00464-015-4481-6

31. Rotermann M. Infection after cholecystectomy, hysterectomy or appendectomy. Heal reports [Internet]. 2004 Jul;15(4):11-23. Available from: http://www.ncbi.nlm.nih.gov/pubmed/15346725 